\title{
Markers of bone turnover in the evaluation of the response to GH treatment in GH-deficient children
}

\author{
Torben Laursen \\ Centre for Clinical Pharmacology, Institute of Pharmacology, Aarhus University, Bartholin Building, DK-8000 Aarhus C, Denmark \\ (Email: torben.laursen@dadlnet.dk)
}

Growth rate and final height are hard end-points when assessing the response to growth hormone (GH) treatment of growth-retarded children. Considering the pronounced variability of height measurements, a 6- to 12-month period of observation is needed to detect a response to GH. Only by employment of the more time-consuming and observer-dependent examination, knemometry (1), can a valid measure of shortterm growth be obtained. Other methods to monitor the effects of GH treatment are therefore sought. Response is known to vary considerably and some children may, in practice, be non-responders, which makes short-term monitoring particularly important. With the prediction of growth response after short-term GH therapy, unnecessary inconvenience for non-responding children and their families, as well as expense for the community, may be avoided. The problem is of particular importance during treatment of children who are not clearly $\mathrm{GH}$ deficient (GHD), such as patients with Turner's syndrome, familial short stature or partial $\mathrm{GH}$ deficiency.

A study in short non-GHD prepubertal children has reported an inverse relationship between spontaneous GH secretion and growth response (2). Thus, an estimation of GH secretory capacity may help to select probable responders before the start of GH therapy. One of the most commonly used markers of GH therapy is insulin-like growth factor (IGF)-I. Serum IGF-I levels, which increase following $\mathrm{GH}$ administration, have been reported to be correlated with growth (3). The effect of $\mathrm{GH}$ on bone metabolism could be either direct or mediated through IGFs or IGF-binding proteins (IGFBP), and IGFBP-3 has also been proposed as a marker of the effects of $\mathrm{GH}$ in bone.

Recently, markers of bone metabolism have been introduced, and changes in their levels during $\mathrm{GH}$ treatment, in particular in its early phase, may be valuable indicators of therapeutic efficacy. GH stimulates bone turnover in GHD patients and in healthy subjects, as reflected by simultaneous increments in the levels of markers of bone formation and resorption in serum or urine $(4,5)$. Positive correlations have been reported between growth velocity and levels of the aminoterminal propeptide of type III collagen (PIIINP) (6), and of the carboxyterminal propeptide of type
I procollagen (PICP) (7), which both reflect bone formation. Early phases of the bone remodelling process generate the amino-terminal propeptide of type I collagen (PINP), being involved in the deposition of collagen, and PIIINP, reflecting extraosseus collagen formation. Type I collagen primarily relates to mineralized bone and soft tissue, whereas type III collagen primarily derives from soft connective tissue (8). The reduced bone turnover in GHD children may be causally associated with a diminished bone mineral density (BMD). To what extent changes in bone dynamics can be translated into increased final height, improved $\mathrm{BMD}$ or enhanced bone strength in adolescence and adulthood is, however, still uncertain.

In this issue of the European Journal of Endocrinology, Baroncelli et al. (14) report on the impact of GH on the dynamics of three different bone markers in GHD children (osteocalcin, PICP, and carboxyterminal telopeptide of type I collagen (ICTP)). Twenty-four children, who have received $\mathrm{GH}$ for 9 years on average, have been followed. The bone matrix protein osteocalcin (OC), reflecting extracellular matrix mineralization, and thus indicative of osteoblast function, and PICP, which is released during secretion of type I collagen, both reflect bone formation. ICTP is a marker of type I collagen breakdown during bone resorption. Levels of all three markers were reduced at baseline, and increased in response to GH therapy, with peak levels attained after 12 months.

Concentrations of the bone markers remained above baseline levels until final height was achieved. However, OC and PICP levels declined while ICTP levels remained stable during the entire observation period. This could suggest a preponderance of resorption relative to formation of bone following longer-term GH therapy. The synthesis of PICP has been reported to be downregulated when bone matrix mineralization is achieved (9). Thus, the observed decrease in levels of formative bone markers might be explained by an enhanced BMD in response to $\mathrm{GH}$ treatment. On the other hand, as Baroncelli et al. state (14), ICTP reflects not only bone resorption, as it is also produced at extraosseus sites, and similarly PICP also derives from fibroblasts. Consequently, they warn against the use of the bone markers as quantitative indices of exclusively bone formation 
and resorption respectively. Finally, data depending on total bone and collagen are also influenced by height and weight, and should therefore probably be corrected for body surface area, weight or urine creatinine (10).

Several other metabolic markers, reflecting bone formation and resorption, have become available during recent years. Serum levels of the bone-specific isoenzyme of alkaline phosphatase is an index of osteoblastic activity, reflecting extracellular matrix formation. Hydroxyproline, a marker of collagen breakdown, has been replaced by markers with improved specificity and sensitivity, allowing a more precise description of GH-induced bone turnover. The crosslinks pyridinoline and deoxypyridinoline, which are formed in type I collagen, are excreted in the urine, and serve as specific markers of bone resorption. Other recently introduced markers of bone resorption are serum and urine levels of N-terminal telopeptide cross-links, and serum crosslap levels.

Concerning the dynamics of bone markers, the results of the present study are largely in accordance with previous reports in untreated GHD patients of reduced circulating levels of bone markers, which increase in response to $\mathrm{GH}$ therapy. In a number of these studies, levels of some of the markers also decreased after longer-term GH exposure. In a study in adult GHD patients, levels of PICP and ICTP increased during the initial 6 months of GH therapy, but had returned to baseline after 42 months, whereas BMD plateaued at a peak level after 36 months (11), indicating that the effect of $\mathrm{GH}$ was conserved despite 'normalized' bone marker levels.

Markers of bone metabolism have been reported to display pronounced inter- and intra-individual, circadian, and day-to-day variability (10). The present study has accounted for sampling conditions and possible circadian and day-to-day variations. These factors were found to be of minor importance in the results.

The decline in the growth rate observed during the 9year study period might reflect a shorter period of pubertal growth in GHD children. Secondly, a decrease in bone turnover may occur with advancing puberty, in parallel with changes in circulating levels of sex hormones. In general, sex hormones increase bone marker levels (e.g. PICP, OC) (12). Down-regulation of markers of bone formation secondary to achievement of a steady-state level of bone matrix mineralization, as mentioned above, could be another explanation. Finally, sensitivity to the GH doses employed may have gradually waned.

The present study disappointingly failed to demonstrate any relationship between short-term (after 6 and 12 months of GH therapy) changes in bone marker levels and long-term growth rate or final height. A previous study reported positive correlations between levels of PIIINP and PICP after 3 months of $\mathrm{GH}$ treatment and relative height score at 12 months (13). The existence of a positive relation between short-term changes in bone turnover and growth has been reported by many, but not all, studies. The hypothesis that levels of bone markers predict the long-term response to $\mathrm{GH}$ was not, however, supported by the present longer-term study. The authors suggest that other factors could influence longitudinal growth independently of the effects of GH on bone turnover. Sex hormones may be proposed as one of these factors. Although BMD measurements in growing children can be associated with errors, it would have been a strength of the present study if BMD data had been available, as a positive relationship might exist between changes in bone turnover and BMD.

Perhaps a realistic expectation would be that early changes in bone marker concentrations predict an essential part of the variability of growth seen in the early phase of GH therapy. Thereby, dynamics of bone turnover could serve as an instrument, giving clinicians an indication of individual responsiveness to $\mathrm{GH}$, where clear increases or lack of changes represent the extreme limits of response.

The difficulties described in finding a single or a few parameters that enable a prediction of the response to $\mathrm{GH}$ treatment is to some degree parallel with the problem in unmasking doping with $\mathrm{GH}$ in sports by one sensitive and specific metabolic marker. In both cases, the employment of a combination of markers reflecting different aspects of $\mathrm{GH}$ action on, for example, bone, circulating $\mathrm{GH}$ isoforms and the IGF axis, may prove to be superior.

In summary, increased knowledge of the dynamics of bone turnover during short- and longer-term GH administration enhances the application of metabolic bone markers in monitoring response to treatment. Even though an optimal growth response to GH cannot be predicted solely by changed bone marker levels, other better indicators are not available. In order to ensure selection of appropriate candiates for $\mathrm{GH}$ treatment a precise diagnosis is necessary. Standard sampling procedures are prerequisites in order to take into account circadian and day-to-day variability and, furthermore, the impact of sex hormone status should be revealed. It may be suggested that the employment of a combination of different specific markers of bone resorption as well as bone formation may be complemented by markers reflecting the IGF axis.

\section{References}

1 Hermanussen M, Sippell WG \& Valk IM. Knemometric monitoring of early effects of human growth hormone on leg length in children with growth hormone deficiency. Lancet 1985 i 1069-1071.

2 Albertsson-Wikland K. Growth hormone treatment in short children - short-term and long-term effects on growth. Acta Paediatrica Scandinavica 1988 (Suppl) 343 77-84.

3 Albertsson-Wikland K \& Hall K. Growth hormone treatment in short children: relationship between growth and serum insulinlike growth factor I and II levels. Journal of Clinical Endocrinology and Metabolism 198765 671-678. 
4 Johansen JS, Jensen SB, Riis BJ, Rasmussen L, Zachmann M \& Christiansen C. Serum bone Gla protein: a potential marker of growth hormone $(\mathrm{GH})$ deficiency and the response to GH therapy. Journal of Clinical Endocrinology and Metabolism 199071 122-126.

5 Schlemmer A, Johansen JS, Pedersen SA, Jørgensen JO, Hassager C $\&$ Christiansen $\mathrm{C}$. The effect of growth hormone $(\mathrm{GH})$ therapy on urinary pyridinoline cross-links in GH-deficient adults. Clinical Endocrinology 199135 471-476.

6 Trivedi P, Hindmarsh P, Risteli J, Risteli L, Mowat AP \& Brook CG. Growth velocity, growth hormone therapy, and serum concentrations of the amino-terminal propeptide of type III procollagen. Journal of Pediatrics $1989114225-230$.

7 Saggese G, Baroncelli GI, Bertelloni S, Cinquanta L \& Di Nero G. Effects of long-term treatment with growth hormone on bone and mineral metabolism in children with growth hormone deficiency. Journal of Pediatrics 1993122 37-45.

8 Eriksen EF, Brixen K \& Charles P. New markers of bone metabolism: clinical use in metabolic bone disease. European Journal of Endocrinology 1995132 251-263.

9 Stein GS, Lian JB \& Owen TA. Relationship of cell growth to the regulation of tissue-specific gene expression during osteoblast differentiation. FASEB Journal 19904 3111-3123.

10 Schonau E \& Rauch F. Markers of bone and collagen metabolism - problems and perspectives in paediatrics. Hormone Research 1997 48 (Suppl 5) 50-59.

11 Valimaki MJ, Salmela PI, Salmi J, Viikari J, Kataja M, Turunen H et al. Effects of 42 months of $\mathrm{GH}$ treatment on bone mineral density and bone turnover in GH-deficient adults. European Journal of Endocrinology 1999140 545-554.

12 Mauras N, Doi SQ \& Shapiro JR. Recombinant human insulinlike growth factor I, recombinant human growth hormone, and sex steroids: effects on markers of bone turnover in humans. Journal of Clinical Endocrinology and Metabolism 1996 $82222-2226$.

13 Tapanainen P, Knip M, Risteli L, Kemppainen L, Kaar ML \& Risteli J. Collagen metabolites in the prediction of response to $\mathrm{GH}$ therapy in short children (see comments). European Journal of Endocrinology $1997137621-625$.

14 Baroncelli GI, Bertelloni S, Ceccarelli C, Cupelli D \& Saggese G. Dynamics of bone turnover in children with GH deficiency treated with GH until final height. European Journal of Endocrinology 2000 $142549-556$

Received 8 March 2000

Accepted 14 March 2000 